\title{
Evaluation of an energy- and exergy-based generic modeling approach of combined heat and power plants
}

\author{
Eike Mollenhauer $^{1} \cdot$ Andreas Christidis $^{1} \cdot$ George Tsatsaronis $^{1}$
}

Received: 4 December 2015 / Accepted: 10 February 2016/Published online: 29 February 2016

(c) The Author(s) 2016. This article is published with open access at Springerlink.com

\begin{abstract}
Reduced models of combined heat and power plants are required for different applications. Among other usages, they are implemented as mixed integer linear programs (MILP) in energy market models or price-based unit commitment problems to study the economic feasibility and optimal operation strategies of different units. Generic models are particularly useful when limited information is available for each considered plant. This paper presents a MILP modeling approach for combined heat and power (CHP) plants. The approach is based on energy and exergy balances and a few typical plant characteristics for different operating conditions. The reduction of electrical power output due to heat extraction is estimated by the transferred exergy to the district heating network. Furthermore, the accuracy, strengths and limitations of this approach are investigated for various CHP plant types with extraction condensing turbines designed for district heating systems. Therefore, detailed thermodynamic cycle simulations of CHP plants including part load operations are used to obtain the real plant operating conditions to compare them to the results of the described generic approach. The validation of the reduced, generic model shows that the accuracy mainly depends on the effectiveness of the heat extraction from the CHP plant. In addition, it can be seen that the main advantage of the presented exergy-based method is the inherent consideration of the feed flow temperature for the calculation of the power reduction due to heat extraction.
\end{abstract}

Eike Mollenhauer

eike.mollenhauer@iet.tu-berlin.de

1 Institute for Energy Engineering, Technische Universität, Berlin, Germany
Keywords CHP, combined heat and power . Cogeneration - MILP, mixed integer linear programs . District heating - Extraction condensing turbine . Thermodynamic simulation · Exergy · Unit commitment
Abbreviations
CCPP Combined cycle power plant
CHP Combined heat and power
DH District heating
HC Heating condenser
MILP Mixed integer linear programs

\section{Introduction}

A lot of countries promote combined heat and power (CHP) plants as they offer a higher efficiency, compared to the separate production of heat and power [9, 15]. In Germany, for example, $15.4 \%$ of the produced electricity in 2010 was generated in CHP plants [8] and the ambitious political target is a share of $25 \%$ in 2020 [19]. The Federal Ministry for Economic Affairs and Energy will prepare the amendment to the CHP Act in 2015 [3]. In other countries, such as for example Denmark, the share is already higher.

CHP plants supply heat and power, so that the optimal operation management is not only influenced by the electricity market, but also by the requirements of the heat customers. This is important to consider in electricity market models which are often implemented as mixed integer linear programs (MILP). MILPs are also used for price-based unit commitment problems, to study optimal operating strategies or economic feasibilities $[7,16,20]$. If studies for general indications for large geographical areas 
are performed, detailed information on the CHP plant characteristics are often unavailable. The generic approach presented here is based on data easy to access and guarantees physical consistency, therefore gives the opportunity to improve these models.

Exergetic considerations are not unusual in the field of CHP plants, as it is one of the possibilities to allocate the costs, fuel consumption or emissions to both products, thermal energy and electrical power [24, 25]. In [12] the legislative efficiency indicators from different countries are exergetically compared. The influence of the steam extraction rate on the exergy destruction in the district heaters is part of [17]. At the end of "Determination of the power loss coefficient", the approach is compared to the "Dresdner Method" [2], which is based on the exergy of the district heating feedwater.

The thermodynamic characteristics of CHP plants are well described in [14] and typical design parameters can be found in $[4,18,27]$.

A wide range of possibilities exist to design combined heat and power plants. They can be classified according to the fuel in gas, oil or coal fired plants whereby oil is uncommon as the main fuel in central CHP plants, due to high and fluctuating prices. Gas turbine plants can be equipped with a heat recovery steam generator (HRSG) and a steam turbine (combined cycle) or only a heat exchanger for district heating to utilize the thermal energy of the exhaust gases. To extract thermal energy from the combined cycle power plant as well as from a coal fired steam power plant, steam from the steam turbine is used. CHP plants can be distinguished in plants with (extraction) back pressure turbine and plants with extraction condensing turbine. Simple schematics of the two heat extraction designs are shown in Fig. 1. Back pressure turbines are characterized by the lack of a condenser. During operation all the steam is condensed in a heating condenser of the district heating system, so that plant operation is only possible during heat demand periods. In extraction condensing steam turbines, it is possible to extract steam from the turbine at one or more pressure stages to feed it into a heating condenser of the district heating system. As it is
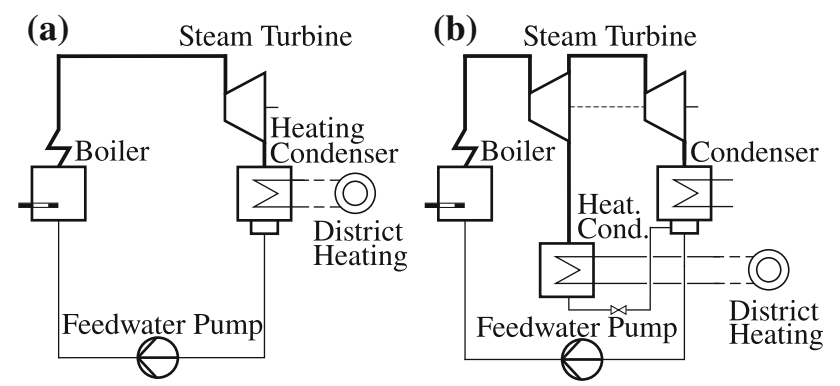

Fig. 1 a Back pressure turbine, b extraction condensing turbine either possible to further expand the steam in the steam turbine down to condenser pressure or to use it for heating of the district heating system, it is useful to define the power loss coefficient $(\beta)$, see (3). It describes the loss of electrical power due to the heat extraction.

The feasible operating conditions of a cogeneration plant can be visualized in a power-to-heat diagram $(P-\dot{Q}$ diagram). Figure 2 shows a simplified example for a plant with a back pressure turbine (a) and one with an extraction condensing turbine (b). The upper boundary is given by the maximum capacity of the boiler and therefore maximum fuel feed, whereas the indicated lower boundary is specified by the minimum capacity of the boiler or the minimum stable load of the gas turbine. On the right hand side with high heat loads the feasible region is restricted by the minimum flow through the last stages of the steam turbine. In some CHP plants the low pressure turbine can be isolated and decoupled so that the complete steam is condensed in the heating condensers. In contrast to CHP plants with extraction condensing turbines which have a feasible operational area in the $P-\dot{Q}$ diagram, plants with a back pressure turbine can only be operated along the back pressure line, see (a) in Fig. 2.

This characteristic line is influenced by various design parameters of the CHP plant as well as operation conditions, like for example the district heating feed or return flow temperature.

Beside the steam extraction from the turbine, further alternatives are possible. In combined cycle power plants (CCPP) a heat exchanger can be installed in the flue gas duct which heats up the district heating water directly. This is especially used in plants with back pressure turbine as the exhaust gas temperature is high. Furthermore, hot condensate could be used for heating the district heating system.

After a short introduction of important key figures of a CHP plant, the approach and a possible integration in MILPs is presented. The approach is based on few basic parameters which are often available for each plant even

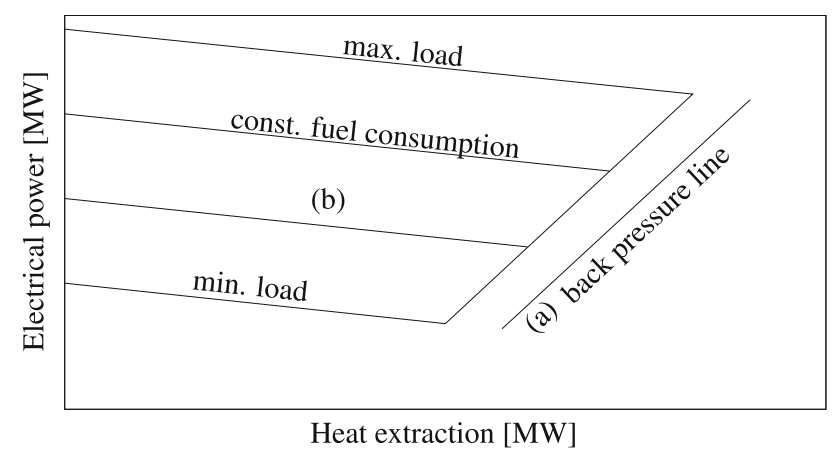

Fig. $2 P-\dot{Q}$ diagram with typical feasible region and its limitations 
during large scale studies and can therefore improve their results. To evaluate the approach, it is compared with thermodynamic simulations of CHP plants designed for district heating supply, see "Validation of the generic modeling approach".

\section{Characteristic figures of cogeneration plants}

An important characteristic of a CHP plant is the power to heat ratio $[9,1]$ which can be defined by

$\sigma=\frac{P}{\dot{Q}}=\frac{\eta_{\mathrm{el}}}{\eta_{\mathrm{th}}}$

where $P$ is the electrical power, $\dot{Q}$ the heat rate extracted for district heating, $\eta_{\mathrm{el}}$ represents the electrical efficiency $\left(\eta_{\mathrm{el}}=P / \dot{H}_{\mathrm{F}}\right)$ and $\eta_{\mathrm{th}}$ the thermal efficiency $\left(\eta_{\mathrm{th}}=\dot{Q} / \dot{H}_{\mathrm{F}}\right)$. The overall energetic efficiency for CHP plants which is also called the energy utilization factor is described in (2):

$\eta_{\mathrm{tot}}=(P+\dot{Q}) / \dot{H}_{\mathrm{F}}=\eta_{\mathrm{el}}+\eta_{\mathrm{th}}$

In Europe the fuel input $\dot{H}_{\mathrm{F}}$ is usually calculated based on the lower heating value of the fuel and the corresponding mass flow. The usable energy of a CHP plant is the sum of electricity or mechanical power and the district heat output.

For a CHP plant with extraction condensing steam turbine the electrical power output is reduced due to the heat extraction, if the fuel rate is kept constant, see Fig. 2. This reduction is characterized by the power loss coefficient $(\beta)$ :

$\beta=-\frac{\left(P(\dot{Q})-P_{\mathrm{woDH}}\right)_{\dot{H}_{\mathrm{F}}}}{\dot{Q}}$

Here, $P_{\mathrm{woDH}}$ is the equivalent electrical power generation without district heat extraction for a constant fuel rate $\dot{H}_{\mathrm{F}}$. The above defined indicators are valid for a given operation point and vary depending on the load, the feed and return flow temperature of the district heating network, and the environmental conditions. The parameters are usually given for full cogeneration mode and maximum load of the boiler or are specified as mean values over a specific time period.

\section{Description of the generic modeling approach}

The considered boundaries for the schematic of a CCPP are shown in Fig. 3, but are also valid for other thermal CHP plants such as coal-fired power plants. For the district heating system and the cooling water, the boundary can be set as shown in the figure, then the flow into and out of the examined system has to be included in the balance. If the boundary is defined on the cold side of the heat exchangers,

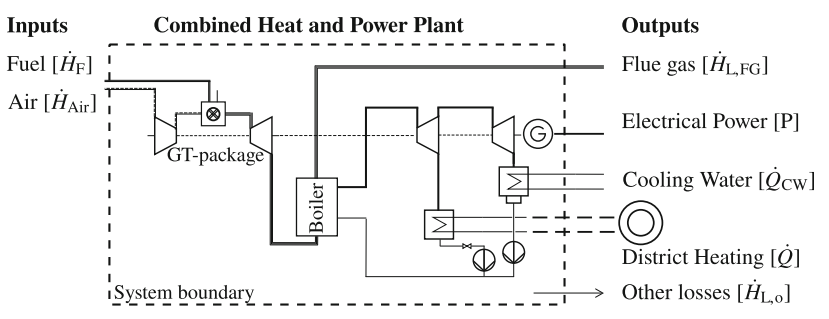

Fig. 3 System boundary of the combined heat and power plant for the overall energy balance

then the energy balance for the entire plant can be defined as in (4).

$\dot{H}_{\mathrm{F}}+\dot{H}_{\mathrm{Air}}=\dot{Q}+P+\dot{H}_{\mathrm{L}, \mathrm{FG}}+\dot{H}_{\mathrm{L}, \mathrm{o}}+\dot{Q}_{\mathrm{CW}}$

Here, $\dot{H}_{\mathrm{L}, \mathrm{FG}}$ are the losses to the environment with the flue gas flow, $\dot{H}_{\mathrm{L}, \mathrm{o}}$ the other losses to the environment.

The generic model uses rudimentary input data of a CHP plant to define the feasible operational range and to link the power and heat output to the fuel consumption. It is based on the idea that the loss of electrical power due to heat extraction can be estimated by the increase of the exergy in the district heating flow (see "Determination of the power loss coefficient").

The following key figures of a plant are sufficient to describe the plant characteristics: the maximum and minimum electrical load without heat extraction $\left(P_{\mathrm{woDH}}\right)$, the electrical efficiency for minimum and maximum load without heat extraction $\left(\eta_{\mathrm{el}}\right)$, the district heating feed and return temperature $\left(T_{\mathrm{FF}}, T_{\mathrm{RF}}\right)$. For the definition of the ambient conditions, the cooling water temperature is required. ${ }^{1}$

The maximum and minimum electrical load defines the cross sections of the feasible operating region and the ordinate in Fig. 2. With the electrical efficiency the fuel consumption $\left(\dot{H}_{\mathrm{F}}\right)$ for these two operating conditions can easily be calculated, see also (12) and (13). The power loss coefficient $(\beta)$ links the electrical power output with the heat extraction in reference to the electrical power without heat extraction $P_{\mathrm{woDH}}$ :

$$
P\left(\dot{H}_{\mathrm{F}}\right)=P_{\mathrm{woDH}}\left(\dot{H}_{\mathrm{F}}\right)-\dot{Q} \cdot \beta
$$

In the $P-\dot{Q}$ Diagram the slope of the lines for constant fuel rate is described by $\beta$ which can be determined with the temperatures of the district heating system according to "Determination of the power loss coefficient".

For maximum fuel rate the maximum extractable heat is given by the power to heat ratio $\sigma$, but for lower fuel rates the assumption of a constant power to heat ratio is an avoidable simplification. In "Determination of the

\footnotetext{
${ }^{1}$ For gas turbine plants the pressure and temperature of the ambient air has to be considered for the performance.
} 
maximum heat extraction" an approach to asses $(\sigma)$ as a function of the boiler load is presented.

\section{Determination of the maximum heat extraction}

With reasonable assumptions it is possible to derive the maximum heat extraction from the energy balance [6]. If the reference point of the enthalpy is set to the ambient air conditions, the left hand side of (4) is reduced to $\dot{H}_{\mathrm{F}}$. The losses to the environment can be estimated as follows. The losses with the flue gas $\dot{H}_{\mathrm{L}, \mathrm{FG}}$ are between 5-10\% for steam power plants $[21,23]$ and the other losses $\dot{H}_{\mathrm{L}, \mathrm{o}}$ are summarized for this work with $1.5 \%$ and added to $\dot{H}_{\mathrm{L}, \mathrm{FG}}$ in further considerations. For CCPPs the losses also depend on the number of pressure levels in the steam cycle. A CCPP with only one pressure level is unable to exploit as much thermal energy from the flue gas as a dual or triple pressure steam cycle. For triple pressure plants the losses are in the same range as for steam power plants, but can increase significantly for inefficient plants with only one pressure level.

Figure 4 shows the effect of flue gas losses on the maximum heat extraction on an example of a one pressure combined cycle power plant, which is further described in "Combined cycle power plant" and Table 1 . The lines for 5-20\% flue gas losses in the right corner result from the energy balance (4) for constant $\eta_{\mathrm{el}}$ and $\beta$ and minimal $\dot{Q}_{\mathrm{CW}}$, see also (7).

If the heat rate to the district heating system shall be maximized, the transferred energy in the condenser $\left(\dot{Q}_{\mathrm{CW}}\right)$ has to be minimized. One typical restriction of a steam turbine is the minimum (cooling) flow through each stage which limits the extracted steam flow to the heating condensers. $^{2}$ Most critical are often the last stages of the low pressure turbine, where the flow conditions change with reduced flow up to ventilation ${ }^{3}$ of the last stages [13]. The minimum flow differs for different steam turbines, but for further considerations a value of $10 \%$ of the nominal mass flow is considered. Therefore, the minimum heat transfer in the condenser $\dot{Q}_{\mathrm{CW} \text {,min }}$ is also roughly ${ }^{4} 10 \%$ of the one at nominal load without steam extraction and can be calculated as follows:

$\dot{Q}_{\mathrm{CW}, \min }=10 \% \cdot\left(\dot{H}_{\mathrm{F}, \max }-\dot{H}_{\mathrm{L}, \mathrm{FG}}-P_{\text {max }, \mathrm{woDH}}\right)$.

Equation (7), derived from (4) and (5), defines the maximum heat rate $\dot{Q}\left(\dot{H}_{\mathrm{F}}\right)$.

\footnotetext{
${ }^{2}$ Maximum allowable steam extraction flows can constitute further constraints.

${ }^{3}$ The isentropic stage efficiency becomes negative.

${ }^{4}$ Even if a small flow to the condenser leads to a reduction of the condensing temperature and pressure, the variation of the enthalpy of evaporation is still small.
}

$\dot{Q}\left(\dot{H}_{\mathrm{F}}\right)=\frac{\left(\dot{H}_{\mathrm{F}}-\dot{H}_{\mathrm{L}, \mathrm{FG}}\left(\dot{H}_{\mathrm{F}}\right)-\dot{Q}_{\mathrm{CW}, \min }\right)-P_{\mathrm{woDH}}\left(\dot{H}_{\mathrm{F}}\right)}{1-\beta}$

With the maximum heat rate, the minimum reachable power to heat ratio $\sigma$ can be calculated with (1), (5) and (7). Obviously not all CHP plants are build for maximum heat extraction as the plants are designed for local requirements, but the approach describes an upper boundary.

\section{Determination of the power loss coefficient}

Due to the steam extraction in the turbine the yield of electrical power is reduced, see (3) and (5). The reduction depends on the pressure of the steam extraction which is again influenced by the required feed flow temperature in the district heating system. The concept of the approach is that the loss of electrical power due to heat extraction can be estimated by the increase of the exergy in the district heating flow. Consequently the influence of the temperatures in the district heating system is accounted for. Even if the power loss coefficient $(\beta)$ is available for a realized CHP plant, this influence is rarely available.

To calculate the exergy difference between the feeding and returning district heating water, the enthalpy and entropy differences of the flows or the transferred heat with the corresponding thermodynamic average temperature can be used. Here, the transferred heat will be used, as the aim of the approach is to describe a plant as simple as possible while containing as many details as possible. If pressure losses are not considered and the heat capacity of the water used in the district heating system is assumed to be constant, the average temperature can be calculated with (8) according to [5].

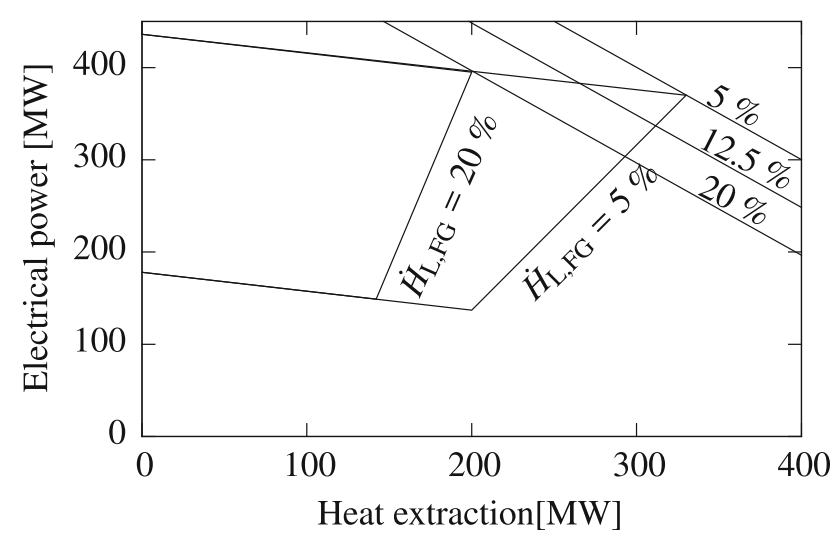

Fig. $4 P-\dot{Q}$ diagram with diffent assumptions for the losses with the fuel gas $\dot{H}_{\mathrm{L}, \mathrm{FG}}$ 
Table 1 Data of the simulated CCPP with 1 and 3 pressure stages and the steam PP

\begin{tabular}{llll}
\hline & 1 Pr. CCPP & 3 Pr. CCPP & Steam PP \\
\hline Max. electrical power (MW) & 436 & 455 & 535 \\
Min. electrical power (MW) & 178 & 190 & 189 \\
Max. steam extraction $\left(3 \mathrm{HC}, 110^{\circ} \mathrm{C}\right)(\mathrm{MW})$ & 201 & 235 & 693 \\
Electrical efficiency (wo DH) $(\%)$ & 57.4 & 59.9 & 41.6 \\
El. eff. minimum stable load (wo DH) $(\%)$ & 48.1 & 51.4 & 37.4 \\
Main steam pressure (bar) & 131 & 131 & 188 \\
Main steam temperature $\left({ }^{\circ} \mathrm{C}\right)$ & 561 & 570 & 540 \\
Hot reheat steam pressure (bar) & NA & 31 & 48.5 \\
Hot reheat steam temperature $\left({ }^{\circ} \mathrm{C}\right)$ & NA & 563 & 540 \\
\hline
\end{tabular}

$T_{\mathrm{M}}=\frac{T_{\mathrm{FF}}-T_{\mathrm{RF}}}{\ln \left(T_{\mathrm{FF}} / T_{\mathrm{RF}}\right)}$

Hereby $T_{\mathrm{FF}}$ is the temperature of the feed flow to the district heating system and $T_{\mathrm{RF}}$ is the return flow. With the mean temperature and the transfered thermal energy $\dot{Q}$, the increase of exergy $\dot{E}_{Q}$ can be calculated to obtain the power loss coefficient:

$\dot{E}_{Q}=\dot{Q} \cdot\left(1-\frac{T_{0}}{T_{\mathrm{M}}}\right) ; \quad \rightarrow \quad \beta=\left(1-\frac{T_{0}}{T_{\mathrm{M}}}\right)$

The reference temperature $T_{0}$ for the exergy calculations shall be set equal to the cooling water inlet temperature.

The Dresdner Method [2] was suggested to estimate the power loss coefficient based on the medium district heating feed temperature of a time period. It uses a typical German condensing temperature and a factor depending on the number of district heaters. In difference to the Dresdner method, the approach described in this work is flexible regarding the cooling water temperature, considers the influence of the district heating return temperature and is independent of the number of district heaters.

\section{The generic MILP model}

In this section the MILP model implementation derived from "Description of the generic modeling approach" is presented. It can be used to describe the steady state characteristics of a CHP plant in a unit commitment problem and should be complemented with dynamic constraints as start-up costs, maximum ramp rates and minimum operation and down time intervals.

A common approach to model a load dependent electric efficiency in MILP models is used in (10) and expanded for heat extraction with the power loss coefficient $(\beta)$ in (11), see "Determination of the power loss coefficient". The binary status variable $\mathbf{Y}$ equals 1 , if the unit is committed or 0, when the unit is not in operation. Equations (12) and (13) account for the operational gap between minimum boiler load and unit shut down and describe the restrictions of minimum and maximum boiler load. The restriction of maximum heat extraction is given by (14), see also "Determination of the maximum heat extraction".

Since it is crucial for a MILP model to distinguish between variables and coefficients, variables are typeset bold. Furthermore all variables have to be defined as positive variables.

$$
\begin{aligned}
\dot{\mathbf{H}}_{\mathbf{F}}(t) & =\alpha_{1} \cdot \mathbf{Y}(t)+\alpha_{2} \cdot \mathbf{P}_{\mathrm{woDH}} \\
\dot{\mathbf{H}}_{\mathbf{F}}(t) & =\alpha_{1} \cdot \mathbf{Y}(t)+\alpha_{2} \cdot \\
& \left(\mathbf{P}(t)+\beta\left(T_{\mathrm{FF}}(t), T_{\mathrm{RF}}(t), T_{0}(t)\right) \cdot \dot{\mathbf{Q}}(t)\right) \quad \forall t \\
\dot{\mathbf{H}}_{\mathbf{F}}(t) & \leq \mathbf{Y}(t) \cdot \frac{P_{\mathrm{max}, \mathrm{woDH}}}{\eta_{\mathrm{el}, \mathrm{max}, \mathrm{woDH}}} \quad \forall t \\
\dot{\mathbf{H}}_{\mathbf{F}}(t) & \geq \mathbf{Y}(t) \cdot \frac{P_{\mathrm{min}, \mathrm{woDH}}}{\eta_{\mathrm{el}, \mathrm{min}, \mathrm{woDH}}} \quad \forall t \\
\mathbf{P}(t) \leq & \dot{\mathbf{H}}_{\mathbf{F}}(t)-\dot{\mathbf{Q}}(t)-\dot{\mathbf{H}}_{\mathbf{L}, \mathbf{F G}}(t)-\dot{Q}_{\mathrm{CW}, \min } \cdot \mathbf{Y}(t) \quad \forall t
\end{aligned}
$$

The coefficients $\alpha_{1}$ and $\alpha_{2}$ are used to describe the electrical efficiency $\left(\eta_{\mathrm{el}}=\mathbf{P} / \dot{\mathbf{H}}_{\mathbf{F}}\right)$ as a function of the boiler load and can be calculated by solving the system of (15) and (16) which results from (10):

$$
\begin{aligned}
\eta_{\mathrm{el}, \mathrm{min}, \mathrm{woDH}} & =\frac{P_{\min , \mathrm{woDH}}}{\alpha_{1}+\alpha_{2} \cdot P_{\min , \mathrm{woDH}}} \\
\eta_{\mathrm{el}, \mathrm{max}, \mathrm{woDH}} & =\frac{P_{\max , \mathrm{woDH}}}{\alpha_{1}+\alpha_{2} \cdot P_{\max , \mathrm{woDH}}}
\end{aligned}
$$

The power loss coefficient $\beta$ is given by Eqs. (8) and (9) for every time step $t$ for predefined ambient, feed and return flow temperatures. The energy loss $\dot{\mathbf{H}}_{\mathbf{L}, \mathbf{F G}}(t)$ can be represented as a percentage of the fuel enthalpy flow rate and is zero for $\mathbf{Y}=0$. The minimal heat transfer in the condenser due to minimum flow conditions in the steam turbine stages $\dot{Q}_{\mathrm{CW} \text {,min }}$ can be obtained from Eq. (6).

One advantage of the utilization of more than just the two obvious variables $P$ and $\dot{Q}$ for the restriction in 
Eq. (14), is that the model stays linear for heat extractions at different feed flow temperatures simultaneously. ${ }^{5}$

Furthermore, the modeling approach can easily be used for CHP plants with back pressure characteristics as well, by replacing $\leq$ by $=$ in (14) and setting the minimum cooling losses $\dot{Q}_{\mathrm{CW} \text {,min }}$ to zero. ${ }^{6}$ The operational area in the $P-\dot{Q}$ diagram is then reduced to the back pressure line, see Fig. 2. Nevertheless, a detailed comparison of the described approach to more accurate simulation results is not part of this work for back pressure turbines.

\section{Validation of the generic modeling approach}

In this section the results of the generic model are compared to the thermodynamic simulations executed with EBSILON ${ }^{\circledR}$ Professional (Ebsilon) [10]. To analyze general correlations, first a combined cycle power plant (CCPP) with one pressure level is simulated. Afterwards, results for a CCPP with three pressure stages, which represents a modern high efficient plant, as well as a steam power plant are discussed and further limitations are shown. For the exergy calculation the ambient and cooling water temperature are set to $15{ }^{\circ} \mathrm{C}$ and the ambient pressure to $1 \mathrm{~atm}$. Some main data of the simulated CHP plants are listed in Table 1.

\section{Combined cycle power plant}

Figures 5 and 7 show the flow sheet digrams from Ebsilon. The following main assumptions were implemented in the CCPP models and the steam power plant model, where applicable:

- The gas turbine is modeled according to the Siemens SGT 4000F characteristics from the gas turbine library distributed by VTU Energy GmbH [26].

- The steam cycle is simulated with sliding pressure as the method for load control; the pressure of each steam turbine stage is defined by the ellipsis law, proposed by Stodola [22].

- Minimum load of the gas turbine and minimum boiler load for the steam power plant is set to $40 \%$ of nominal load.

\footnotetext{
${ }^{5}$ If this restriction is empirically modeled by only using $P$ and $\dot{Q}$, the weighting factors $\frac{\dot{Q}_{T}}{\sum_{T} \dot{Q}_{T}}$ for the superposition of the characteristic parameters for different maximum heat restrictions for the different feed flow temperatures become non-linear and far "less powerful" MINLP solvers have to be used.

6 The electric efficiencies used in (12) and (13) are not valid for the back pressure line and have to be calculated by taking (5) into account.
}

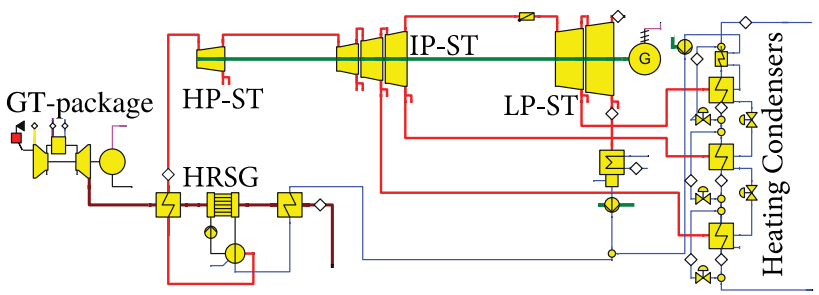

Fig. 5 Flowsheet of the simple CCPP with one heating condenser

- A pressure control flap is installed in the overflow steam line from the IP to the LP turbine, which is often used to control the condensing temperature in the district heaters.

- $T_{\mathrm{RF}}=60^{\circ} \mathrm{C} ; \quad T_{\mathrm{FF}}=90 / 110 / 130{ }^{\circ} \mathrm{C}$

In full condensation mode approximately two thirds of the electrical power of a CCPP is generated in the gas turbine, so that the influence of the steam extraction is limited to the remaining third of the steam turbine.

Combined cycle power plant with single-pressure boiler Figure 5 shows the flow diagram for the CCPP with a single-pressure boiler. The CHP plant with three district heaters is presented, but similar models were analyzed with one and two district heaters as well. ${ }^{7}$ This basic example is used to analyze the influence of the number of heating condensers but also shows the influence of the energetic losses (here referred to as flue gas losses) for CCPPs.

Figure 6 shows the influence of a different number of heating condensers and compares the simulations with the approach.

A higher number of heating exchangers reduces the exergy destruction of the heat transfer, increases the utilization of steam in the steam turbine and reduces the throttling losses of the control flap. Therefore, the power loss coefficient decreases with the number of heating condensers. Nevertheless, for the analyzed cases the differences are small for different reasons. First, the small mass flow through the remaining stages of the turbine downstream the extractions reduces the pressure and enthalpy differences as well as the isentropic efficiency of the last turbine stages. Hence, the generated mechanical power in these stages is small compared to the overall power production. Second, in the models with two and three district heaters the pressure on the low pressure steam extraction is so low that the condensing temperature is only slightly above the district heating return flow temperature. Therefore, only a small amount of steam is fed to the first district heater. However, the installation of multiple heating exchangers offers the opportunity to satisfy low-

\footnotetext{
${ }^{7}$ If only two district heaters are installed, the one with the highest extraction pressure is neglected and in case of one district heater only the intermediate one is considered.
} 
Fig. $6 P-\dot{Q}$ diagram with typical feasible region for 1,2 and 3 heating condensers compared to the approach

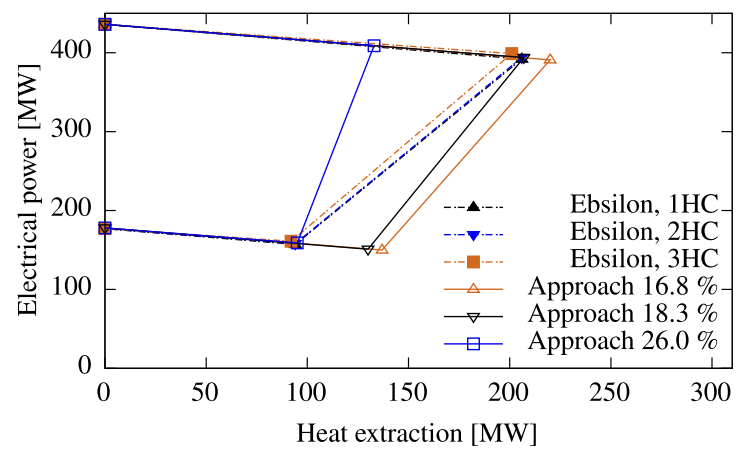

temperature heat demands only with the low pressure district heater(s), so that no steam has to be extracted from one of the high pressure extractions for this purpose.

Furthermore, the figure illustrates that the simulated CHP plants are unable to extract as much heat as the so far described approach estimates. The losses with the flue gas for nominal load without heat extraction are $\left(\dot{H}_{\mathrm{L}, \mathrm{FG}}=16.8 \%\right)$ of the fuel feed $\left(\dot{H}_{\mathrm{F}}\right)$ in the simulation but it increases to $18.3 \%$ for maximum district heating.

The difference can be explained by the increase of the condensate inlet temperature of the boiler which leads to higher losses with the flue gas. ${ }^{8}$

In the considered example with one heating condenser and a feed flow temperature of $T_{\mathrm{FF}}=110^{\circ} \mathrm{C}$ the condensate temperature increases from $30{ }^{\circ} \mathrm{C}$ without district heating to $61{ }^{\circ} \mathrm{C}$ with maximum district heating. This correlation heavily depends on the condensate preheater inlet temperature during operation without heat extraction and the district heating return flow temperature $\left(T_{\mathrm{RF}}\right)$. Usually the condensate temperature at the inlet of the boiler is determined based on the dew-point temperature of the flue gas. Therefore, recirculations, bypasses and other measures are taken to control this temperature. These measures are not considered in the model, so that this effect is overestimated. If the additional losses were considered in the approach, the results match the simulation well, see graph for $18.3 \%$ in Fig. 6.

Another noticeable difference is a significant reduction of the maximum heat extraction for minimum stable load, which results from increased losses with the exhaust gas ( $\left.\dot{H}_{\mathrm{L}, \mathrm{FG}}\right)$ during part load operation of CCPPs independent of the district heating. Hence, in addition to the change of condensate temperature as for nominal load, the energetic losses increase up to $26 \%$ of the fuel rate for minimum power generation and maximum heat extraction of the CCPP.

\footnotetext{
8 This effect is only relevant for CCPPs and does not occur at steam power plants, because the condensate preheating in steam power plants is realized with steam extractions from the steam turbine instead of heat exchangers in the flue gas system.
}

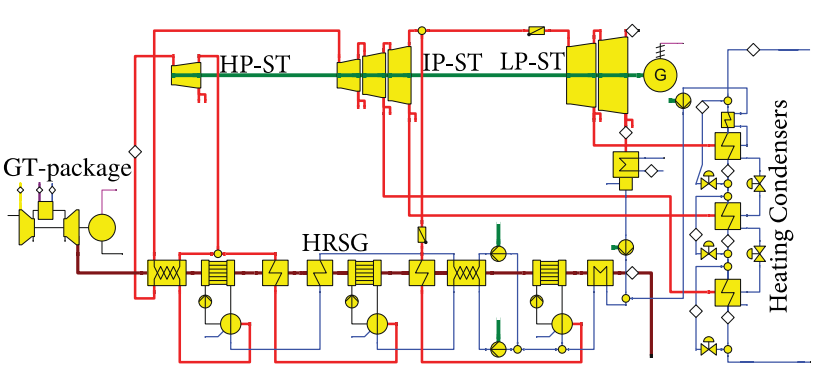

Fig. 7 Flowsheet of CCPP with three steam pressures

In summary, Fig. 6 shows, that the differences between the thermodynamical simulations with different number of heating condensers are small for maximum heat extraction in the analyzed example. In addition it illustrates, that the approach overestimates the possible heat extraction, if the relative exhaust gas losses in full load without heat extraction $(16.8 \%)$ are used for part load. If the increased flue gas losses at maximum heat extraction are considered (18.3\% in full load and $26 \%$ in minimum load) the results of the detailed thermodynamic simulations and the approach with constant flue gas losses match for the particular load cases. Hence, more accurate results can be obtained, if load dependent flue gas losses are considered, given that this dependency is known.

It can be stated that the restriction for maximum heat extraction is strongly influenced by the flue gas losses, see also "Determination of the maximum heat extraction" and Fig. 4, which can vary with the gas turbine load and the amount of heat extraction, as shown above.

Combined cycle power plant with triple pressure boiler The flow sheet of the CCPP model with triple pressure boiler is shown in Fig. 7.

Figure 8 shows the effect of the district heating feed flow temperature $\left(T_{\mathrm{FF}}\right)$ on the possible operating conditions and compares the simulation results with the generic modeling approach. The energetic losses $\dot{H}_{\mathrm{L}, \mathrm{FG}}$ for the generic approach are set to be equal to the losses of the thermodynamic model in nominal load without district heating $(8.7 \%)$. In nominal GT load and maximum heat 
Fig. $8 \quad P-\dot{Q}$ diagram of combined cycle power plant
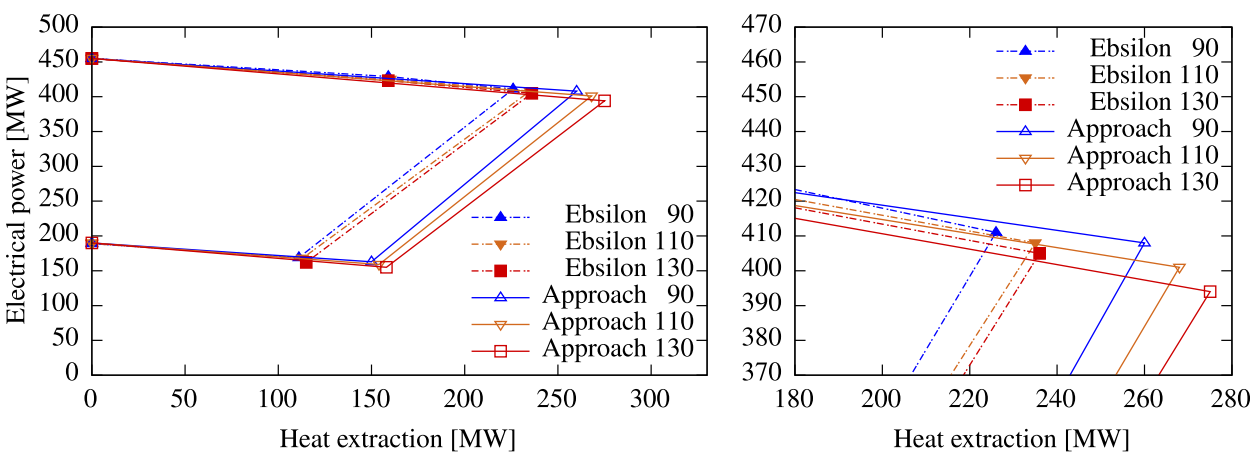

extraction they increase to $9.9 \%$, due to the higher condensate temperature, as described in "Combined cycle power plant". In addition to this effect, the approach predicts higher possible district heating capacities due to higher steam flows to the condenser in the simulation. In this example, the superheated low-pressure steam is fed to the LP turbine, which results in a sufficient flow through the last steam turbine stage even with maximum district heating. The limitation to be considered, is to ensure the minimum flow through the last intermediate pressure stage, so that the minimal flow to the condenser increases to $18 \%$ instead of $10 \%$ of the nominal flow.

Hence, the increased flue gas losses as well as the higher heat transfer in the condenser reduce maximum heat extraction, see also (7) where both parameters could be summated.

The power loss coefficient increases with rising feed flow temperature of the district heating system $\left(T_{\mathrm{FF}}\right)$, as it requires higher extraction pressures and shifts the load share between the heating condensers.

Compared to the detailed Ebsilon simulations, the approach indicates the general trends, but does not exactly meet the simulation results which always depend on the specific design parameters of the plant. Figure 8 includes some additional values for maximum fuel and medium steam extraction, which is why a slightly non linear trend of the upper map restriction can be seen for the Ebsilon results. The trend for $110{ }^{\circ} \mathrm{C}$ is well predicted, for $90{ }^{\circ} \mathrm{C}$ the simulation model has a higher power loss coefficient as the approach predicts for maximum steam extraction. For $90{ }^{\circ} \mathrm{C}$ and lower steam extraction the power loss coefficient fits the approach better. The steep drop is due to a load shift from the first to the second district heater, if the heat extraction is increased from 160 to $225 \mathrm{MW}$. For a feed temperature of $130{ }^{\circ} \mathrm{C}$ the results of the approach overestimate the power loss. The extracted heat for $130{ }^{\circ} \mathrm{C}$ is nearly the same as for $110{ }^{\circ} \mathrm{C}$, due to the limitation of the minimum flow through the IP stage which is not considered in the simple generic modeling approach. If the steam extraction for the high-pressure district heater could have

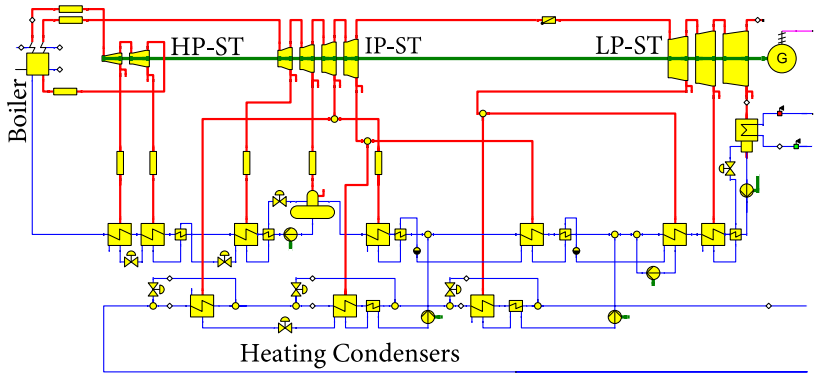

Fig. 9 Flowsheet of steam turbine power plan

been increased, the heat extraction and the power loss would have been higher.

\section{Steam power plant}

In the steam CHP plant, the steam is similarly extracted from the steam turbine. In contrast to the CCPP, the feed water is heated by condensate preheaters with steam from the steam turbine and not by flue gas. The flow sheet of the simulated model is shown in Fig. 9.

The steam extraction for district heating reduces the steam which is available for the low-temperature preheaters. For maximum boiler load the thermal energy transferred in the preheaters, which extract steam from the LP turbine, decreases from 147 to $18 \mathrm{MW}$, compared to the operation without heat extraction. The transferred thermal energy in the residual preheaters, including feed water tank, increases accordingly from 361 to $447 \mathrm{MW}$ (also discussed by [17]).

The $P-\dot{Q}$ diagram for the steam power plant in Fig. 10 shows the influence of $T_{\mathrm{FF}}$ and the comparison with the approach. For $T_{\mathrm{FF}}=90^{\circ} \mathrm{C}$ and $T_{\mathrm{FF}}=110^{\circ} \mathrm{C}$ the operation field of the simulations concur well with the presented approach. For $T_{\mathrm{FF}}=130^{\circ} \mathrm{C}$ the model has a higher reduction of electrical power than the approach. The main factor is that compared to the load case with $T_{\mathrm{FF}}=110^{\circ} \mathrm{C}$, the $T_{\mathrm{FF}}=130^{\circ} \mathrm{C}$ case requires a higher pressure in the overflow line, which leads to higher exergy destruction due 


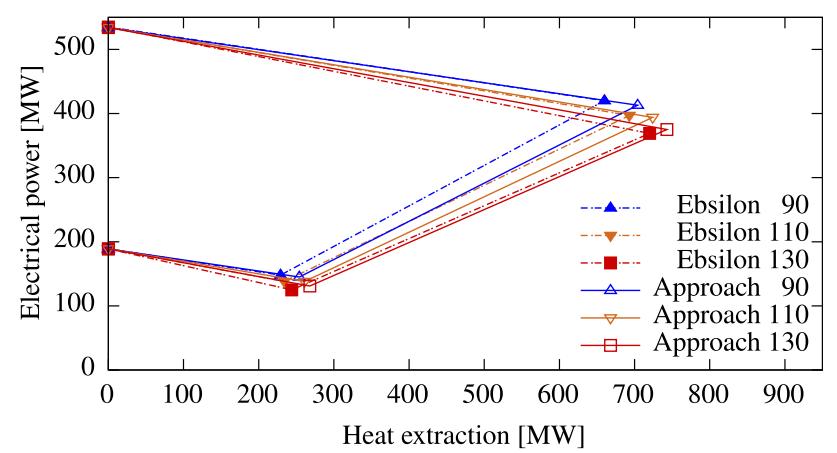

Fig. $10 P-\dot{Q}$ diagram for steam power plant with three different feed temperatures compared to the approach

to throttling in the control valve and to a reduction of power generation in the two upstream steam turbine stages.

\section{Further individual limitations for real plants}

In realized plants additional limitations might occur. Among others these can be:

- A flow limitation for each steam extraction.

- High feed temperatures might not be reachable due to the pressure reduction on the extraction points; possible solution: installation of a control valve, additional tapping on the steam turbine.

- The flow in the district heating system can be limited hydraulically, which leads to vertical restrictions in the $P-\dot{Q}$ diagram.

- Not all CHP plants can run on full load without steam extraction.

- Not all plants are designed for maximum steam extraction $\left(\dot{Q}_{\mathrm{CW}, \min }>10 \%\right)$.

\section{Conclusions}

The presented modeling approach offers the opportunity to predict and describe the performance characteristics of a combined heat and power plant based on very few key figures and reasonable assumptions, see "Description of the generic modeling approach" and "The generic MILP model". It respects thermodynamic limitations and considers the influence of seasonal fluctuations typical for CHP plants, as it incorporates changes in the temperatures of the district heating system and can be adjusted to different site conditions (e.g. cooling water temperature).

A way to derive the power to heat ratio from the energy balance of the plant is presented in "Determination of the maximum heat extraction". Even if an individual plant might have a lower ratio, the introduced procedure guarantees that the first law of thermodynamics is not violated.
The power loss coefficient is approximated with the exergy transfered to the district heating system, see "Determination of the power loss coefficient". The comparison with simulations in "Validation of the generic modeling approach" shows that the characteristics for typical CHP plant designs for district heating supply can be well expressed with the presented approach.

Nevertheless, based on different local requirements a high variety of CHP plants exist, which can not be represented explicitly by a generic model. Therefore, detailed information of the examined plants should always be preferred, whenever available.

Acknowledgments This work was developed during the research project "Thermal storages for increased flexibility of CHP plants" [11], funded by the German Federal Ministry for Economic Affairs and Energy (BMWi) with the project reference number 03ET1188A.

Authors' contributions EM carried out the computational simulation and analysis and drafted the manuscript. AC proposed the concept of the approach, checked the analysis, revised the manuscript and drafted "Description of the generic modeling approach". GT provided technical guidance and a review of the manuscript. All authors read and approved the final manuscript.

\section{Compliance with ethical standards}

Conflict of interest The authors declare that they have no competing interests.

Open Access This article is distributed under the terms of the Creative Commons Attribution 4.0 International License (http://crea tivecommons.org/licenses/by/4.0/), which permits unrestricted use, distribution, and reproduction in any medium, provided you give appropriate credit to the original author(s) and the source, provide a link to the Creative Commons license, and indicate if changes were made.

\section{References}

1. AGFW: AGFW-Arbeitsblatt FW 308. Certification of CHP plants. Determining the CHP electricity (2011)

2. AGFW: Arbeitsblatt AGFW FW309 Teil 6-Entwurf (2012)

3. BMWI: an electricity market for Germanys energy transition. In: Discussion Paper of the Federal Ministry for Economic Affairs and Energy (Green Paper). Federal Ministry for Economic Affairs and Energy (BMWi) (2014)

4. Baehr: Konzeption und Aufbau von DKW. Technischer Verlag Resch (1985)

5. Bejan, A., Tsatsaronis, G., Moran, M.: Thermal Design and Optimization. Wiley, New York (1996)

6. Christidis, A., Tsatsaronis, G.: Das ökonomische Potential von Wärmespeichern bei Heizkraftwerken im heutigem Strommarkt. In: VDI-Berichte Nr. 2157, 2011, 9. Fachtagung "Optimierung in der Energiewirtschaft", pp. 223-240 (2011)

7. Christidis, A., Koch, C., Pottel, L., Tsatsaronis, G.: The contribution of heat storage to the profitable operation of combined heat and power plants in liberalized electricity markets. Energy 41(1), 75-82 (2012). doi:10.1016/j.energy.2011.06.048. http:// www.sciencedirect.com/science/article/pii/S0360544211004348 
8. Cogen Europe: European cogeneration review-a series of country reports on cogeneration in European countries-Germany. In: Technical report, Cogen Europe (2013)

9. Directive 2004/8/EC of the European Parliament and of the Council (2004)

10. Ebsilonprofessional: http://www.steag-systemtechnologies.com/ ebsilon_professional+M52087573ab0.html. Accessed 25 February 2015 (2015)

11. EnEff-Wärme: Thermische Speicher für die Flexibilisierung von KWK-Anlagen. In: Technical report. http://www.eneff-stadt.info/ de/waerme-und-kaeltenetze/projekt/details/thermische-speicherfuer-die-flexibilisierung-von-kwk-anlagen/ (2014)

12. Ertesvåg, I.: Exergetic comparison of efficiency indicators for combined heat and power (CHP). Energy 32(11), 2038-2050 (2007). doi:10.1016/j.energy.2007.05.005. http://www.sciencedir ect.com/science/article/pii/S0360544207000916

13. Grote, W.: Ein Beitrag zur modellbasierten Regelung von Entnahmedampfturbinen. Ph.D. thesis, Ruhr-Universitt Bochum (2009)

14. Horlock, J.: Cogeneration: Combined Heat and Power-Thermodynamics and Economics. Pergamon Press, Oxford (1987)

15. IEA: Cogeneration and district energy. In: Technical report, OECD-International Energy Agency (2009). http://www.iea. org/publications/freepublications/publication/CHPbrochure09.pdf

16. Jüdes, M., Christidis, A., Koch, C., Pottel, L., Tsatsaronis, G.: Combined optimization of the operation of existing power plants with the design and operation of heat storage systems for a large district heating network. In: Proceedings of the 22nd International Conference on Efficiency, Cost, Optimization, Simulation and Environmental Impact of Energy Systems, 31 August-3 September 2009, Foz do Iguau, Paran, pp. 291-300 (2009)

17. Kail, C., Haberberger, G.: Technik und Kosten der Kraft-WärmeKopplung bei GUD- und Dampfkraftwerken. VDI-Berichte 1495, 99-112 (1999)
18. Kehlhofer, R., Kunze, N., Lehmann, J., Schller, K.H.: Gasturbinenkraftwerke, Kombikraftwerke. Technischer Verlag Resch, Heizkraftwerke und Industriekraftwerke (1984)

19. Prognos: Massnahmen zur nachhaltigen Integration von Stromund Wärmebereitstellung in das neue Energieversorgungssystem. In: Technical report (2013)

20. Scarabello, G., Rech, S., Lazzaretto, A., Christidis, A., Tsatsaronis, G.: Optimization of thermal power plants operation in the German de-regulated electricity market using dynamic programming. In: Proceedings of the ASME 2012 International Mechanical Engineering Congress and Exposition, pp. 147-160 (2012)

21. Spliethoff, H.: Flexible und effiziente Kohlekraftwerke. In: VDIFachkonferenz: Flexibilitts- und Effizienzsteigerung von Bestandskraftwerken. VDI Wissensforum, Stuttgart, pp. 1-14 (2010)

22. Stodola, A.: Dampf-und Gasturbinen. Verlag von Julius Springer, Berlin (1924)

23. Strauss, K.: Kraftwerkstechnik-zur Nutzung fossiler, nuklearer und regenerativer Energiequellen. Springer, Berlin (2006)

24. VDI: VDI4660 - Calculation of Emissions Related to Target Energy for Energy Conversion, Part 2 (2003)

25. VDI: VDI4608-Energy Systems - Combined Heat and Power Allocation and Evaluation, Part 2 (2008)

26. VTU Gasturbine Library: http://www.vtu-energy.com/Gasturbi nenBibliothek/en/1746. Accessed 25 February 2015 (2015)

27. Winkens, H.P.: Heizkraftwirtschaft und FernwarmeversorgungEinKompendium. Verlags- und Wirtschaftsgesellschaft der Elektrizittswerke m.b.H-VWEW (2000) 